\title{
Estudio y lucha: memorias del movimiento estudiantil universitario salvadoreño en el contexto neoliberal de posguerra
}

\author{
Alan Marcelo Henríquez Chávez ${ }^{1}$
}

\section{Resumen}

Recepción: 25 de julio de 2018 / Aceptación: 28 de setiembre de 2018

Se discute la desarticulación de la Asociación General de Estudiantes Universitarios Salvadoreños (AGEUS) recuperando las memorias de dos exmilitantes durante el período 1992-2000 recolectadas utilizando entrevistas semiestructuradas ${ }^{2}$. Se busca comprender cómo, en el contexto de nuevas garantías civiles de la posguerra, AGEUS se desarticula a menos de diez años de la firma de los Acuerdos de Paz (1992), habiéndose mantenido activa desde 1927. El análisis se desarrolla en tres momentos: un esbozo del papel histórico de la AGEUS, una descripción resumida del impulso neoliberal de principios de la década de 1990 y el análisis de las memorias de dos militantes del último período de actividad de AGEUS. Las conclusiones permiten cuestionar la forma en que el FMLN coordinó su transición de guerrilla a partido político, haciendo recurso de los líderes de movimientos sociales.

\section{Palabras clave}

El Salvador; AGEUS; estudiantes; posguerra; neoliberalismo

\section{Abstract}

The article deals with the dissolution process of the de General Association of Salvadoran University Students (AGEUS) using as oral sources the memorials of two former militants from the 1992-2000 period. The discussion aims to understand how, in a context of new civil liberties and guarantees, an association with reported activity since 1927 is dismantled less than ten years after the Peace Agreements (1992). The document is structured in three parts: a brief description of the Association's historic relevance, a

1 Salvadoreño. Licenciado en Psicología por la Universidad Centroamericana José Simeón Cañas (UCA) y máster en Historia Moderna y Contemporánea por el Instituto de Investigaciones Dr. José María Luis Mora, México. Actualmente cursa la maestría en Resolución de Conflictos, Paz y Desarrollo en la Universidad para la Paz (UPEACE) en Costa Rica. Correo electrónico: ahenriquez@master.upeace.org

2 Las impresiones se retoman de un grupo mayor de entrevistas que realizaron Ricardo Alejandro Durán Rodríguez, Ricardo Ernesto Rivera Chinchilla y el autor en el año 2013 en el marco de su tesis de licenciatura en psicología La Asociación General de Estudiantes Universitarios Salvadoreños (AGEUS) como grupo en los contextos socio-históricos de 1984 a 1991 y de 1992 a 200: abordaje desde un modelo psicosocial. El estudio tiene el propósito de conocer el funcionamiento interno y externo de la organización. Los aportes permitieron conocer la estructura y funcionamiento internos de AGEUS durante ambos períodos así como sus estrategias y acciones de articulación con otros movimientos sociales, especialmente el magisterial, sindical y obrero. Para acceder a las entrevistas, los lectores pueden contactar con el autor de este artículo por medio del correo indicado en la nota anterior. 
summarized explanation of the neoliberal adjustments of the postwar period in El Salvador, and selections from the memoirs of two former militants in the Association's last period of activity. The conclusions allow to question the mechanisms the FMLN guerrilla used for its transition to a political party, taking leaders of the social movements and some of them without direction in the process.

\section{Keywords}

EI Salvador; AGEUS; students; postwar; neoliberalism

\section{Resumo}

A desarticulação da Associação Geral de Estudantes Universitários de El Salvador (AGEUS) é discutida através da análise das memórias de dois ex-membros durante o período 1992-2000, coletados por meio de entrevistas semi-estruturadas. Procurouse entender como, no contexto de novas garantias civis do período pós-guerra, a AGEUS se desmantela menos de dez anos após a assinatura dos Acordos de Paz (1992), sendo que havia permanecido ativa desde 1927. A análise é desenvolvida em três etapas: um esboço do papel histórico de AGEUS, uma descrição sumária do impulso neoliberal do início da década de 1990 e, a análise das memórias de dois militantes do último período de atividade de AGEUS. As conclusões nos permitem questionar as maneiras pelas quais a FMLN coordenou sua transição de guerrilha para partido político, se fazendo valer dos líderes dos movimentos sociais.

\section{Palavras chave}

El Salvador; AGEUS; estudantes; pós-guerra; neoliberalismo

\section{El papel histórico de la Asociación General de Estudiantes Universitarios Salvadoreños (AGEUS): del martinato a la guerra civil}

El principio de las actividades políticas de la AGEUS se remonta a los orígenes de los movimientos de izquierda en El Salvador. Fundada por Agustín Farabundo Martí, Alfonso Luna y Mario Zapata como resultado de la intensa actividad organizativa de los movimientos populares a principios de la década de 1920, la AGEUS aglutinó con su fundación esfuerzos anteriores de movilización estudiantil que no habían logrado trascender a las coyunturas que los provocaron (Quezada y Martínez, 2008, p. 30).

Durante esta década surgieron otras organizaciones como la Federación Regional de Trabajadores Salvadoreños (FRT) en 1924, y, eventualmente, el Partido Comunista Salvadoreño (PCS) en 1930. Los sucesos de 1932 marcaron un punto de quiebre para todas estas organizaciones, siendo muchos de sus dirigentes, entre ellos Martí, Luna y Zapata, ejecutados por fusilamiento el 1 de febrero del mismo año. Asimismo, aproximadamente miles 
de campesinos ${ }^{3}$ fueron asesinados como parte de la represión ordenada por el gobierno para aplacar la revuelta. La insurrección se prolongó del 23 al 25 enero y su saldo fue tanto el bautizo de sangre del régimen del general Maximiliano Hernández Martínez como el del período de dictaduras militares que se prolongaría por más de medio siglo en El Salvador.

A partir de la masacre de 1932, el régimen del general Hernández Martínez impuso una serie de medidas represivas como la prohibición de los sindicatos y los partidos políticos, a excepción del partido del régimen, la conformación de una red de espionaje dentro de la Policía Nacional, la revisión de correspondencia, la censura de la prensa y un estado de sitio que se prolongaría todo su período (Walter citado en López, Quinteros y Ramos, 2015, p. 299). De acuerdo con Paul Almeida (2011, p. 76), en su estudio sobre movilizaciones populares en El Salvador, la represión masiva posterior al levantamiento destruyó totalmente la infraestructura organizacional que se había establecido en la última parte de los años veinte y a inicios de los años treinta del siglo pasado alrededor de la FRT y otros grupos.

La dictadura del General Hernández Martínez se extendería hasta 1944 cuando diversos sectores sociales se organizaron en una huelga general que pasó a conocerse como "huelga de brazos caídos", en la que los estudiantes universitarios organizados tuvieron un resurgimiento el 19 de abril encadenando las puertas de la Universidad de El Salvador (UES), ejemplo que seguirían los estudiantes de primaria y secundaria (Quezada y Martínez, 2008, p. 32). Con la caída del General Martínez inició un período en el que se sucedieron en el poder gobiernos militares "reformistas" que perseguían sacar al país del impase económico, producto de la caída del modelo agroexportador, a través de la industrialización.

A pesar del discurso oficial de apertura política, durante los gobiernos militares posteriores a la dictadura de Martínez persistieron las medidas represivas, como el decreto de un nuevo estado de sitio en marzo de 1951 justificado por una supuesta doble conspiración desde la izquierda y la derecha para desestabilizar el gobierno (Turcios citado en López, Quinteros y Ramos, 2015, p. 93). La escalada represiva impulsada por el Partido Revolucionario de Unificación Democrática (PRUD), fundado a partir del concejo de gobierno que derrocó al general Salvador Castaneda Castro en 1948, tuvo como respuesta de la sociedad civil el fortalecimiento del movimiento obrero y su articulación con otros sectores como el estudiantil.

3 El número de víctimas de la represión en el marco del levantamiento es un frecuente objeto de discusión en la abundante historiografía sobre la matanza. Las fuentes disponibles no han permitido afirmar con certeza las cifras de muertos ocurrida durante esta. Miguel Mármol, sobreviviente de la masacre, señala que fueron aproximadamente 20000 muertos producto de las dos semanas que duró el operativo. Por otra parte, Thomas Anderson, en un estudio desarrollado hacia 1970, estimó la cifra en 8000 personas. Para profundizar la revisión del debate ver: Ching, Tilley y López (2007); Anderson (1971) y Dalton (1997). 
En octubre de 1959, la Confederación General de Trabajadores Salvadoreños y la AGEUS, con la participación de todos los partidos de oposición, constituyeron el Frente Nacional de Orientación Cívica con el objetivo de tener una ley electoral democrática. El 19 de agosto de 1960, la Asamblea endureció los controles sobre las manifestaciones públicas y el 2 de septiembre del mismo año tropas del ejército tomaron por asalto la Universidad Nacional atropellando al rector y encarcelando a muchos estudiantes (Turcios citado en López, Quinteros y Ramos, 2015, pp. 94-95).

Ese mismo año, el 26 de octubre, el golpe de Estado al general Lemus puso fin al prudismo y marcó el inicio de un importante auge de las organizaciones populares. La inspiración del triunfo de la Revolución Cubana de 1959 marcó significativamente la década de 1960 para todos los países de Latinoamérica y El Salvador no fue una excepción. Durante este período, según demuestran estudios como el de Cabarrús (1983), se lograron importantes avances en la organización popular, especialmente obrera y campesina, y los estudiantes universitarios no se mantuvieron al margen de estos procesos.

Los movimientos sociales durante la década de 1960 intensificaron su actividad de lucha y se tuvieron hitos en la lucha obrera como la huelga general progresiva de 1966 y 1967, la huelga de trabajadores de la fábrica ACERO, de la fábrica IUSA, la de transportistas de San Salvador de 1967 y la huelga general de maestros de 1968 (Turcios ciatdo en López, Quinteros y Ramos, 2015, p. 99). Sin embargo, quizás el paso más importante, en términos organizativos, que se toma en esta década es la fundación del Frente Unido de Acción Revolucionaria (FUAR), entre 1961 y 1963, como iniciativa de diversas organizaciones populares y el Partido Comunista Salvadoreño.

De acuerdo con datos presentados por Almeida (2011, p. 120), entre 1960 y 1971 la población estudiantil de la UES se quintuplicó de 2229 a 12392 y su infraestructura se triplicó en tamaño con la construcción de un campus central que acuerparía las anteriormente dispersas instalaciones académicas y la apertura de los campus en Santa Ana en 1965 y San Miguel en 1969. Durante este período, el Estado toleró la persistencia y renovación de las organizaciones estudiantiles que se articularon con otros actores de la sociedad civil, especialmente con la causa magisterial.

Entrada la década de 1970, las organizaciones sindicales habían crecido significativamente y, con la década de expansión educativa recién descrita, la AGEUS también. Dentro de la organización, sin embargo, proliferaron otros grupos que se diferenciaron políticamente, como el Frente Estudiantil Universitario Revolucionario (FEUR), el Frente de Acción Universitaria (FAU), la Federación Revolucionaria de Estudiantes Social Cristianos (FRUSC), la Acción Católica Universitaria Salvadoreña (ACUS) y el Frente Socialista 202 Demócrata (FSD) (Almeida, 2011, p. 135). 
Lo anterior es reflejo de dos importantes procesos dentro de la AGEUS: primero, la diversificación de tendencias políticas dentro de su estructura visibilizó la heterogeneidad de los intereses y líneas ideológicas dentro de la misma universidad y, segundo, marcaría una tendencia de disputas internas que se mantendría hasta su disolución a finales de la década de 1990. Documentos como los boletines, cartas abiertas y números de publicaciones como Opinión Estudiantil son un claro registro de las múltiples, y en momentos cruentas, disputas dentro del movimiento estudiantil universitario.

La escalada del descontento social, la creciente organización popular y las respuestas cada vez más represivas del Estado marcaron la década de 1970 como escenario histórico en el que se consolidarían las primeras organizaciones abiertamente político-militares y olas de protesta cada vez más grandes y disruptivas. Asimismo, sería en esta década que sucederían dos de los momentos previos a la guerra civil más decisivos para el movimiento estudiantil universitario: la ocupación militar del campus central de la UES el 19 de julio de 1972, que dejó como saldo 800 estudiantes arrestados y el destierro del personal administrativo a la Nicaragua de Somoza, y la masacre de estudiantes del 30 de julio de 1975, perpetrada por cuerpos de seguridad del Estado, cuyo saldo fueron por lo menos 20 estudiantes de la UES y de secundaria muertos o desaparecidos (Almeida, 2011, pp. 178-213).

Durante estos años, dentro del movimiento universitario comenzaron a definirse algunos cuadros de liderazgo de lo que serían los frentes guerrilleros que conformarían el FMLN, como Francisco Jovel y Medardo González. Otros pasarían a ser recordados como mártires de la causa revolucionaria, como Felipe Peña, Gloria Palacios y Rafael Arce Zablah, cuyo nombre abanderó a las fuerzas especiales del Ejército Revolucionario del Pueblo (ERP) en la guerra civil (Quezada y Martínez, 2008, p. 49).

La década de 1970 termina con un movimiento estudiantil fortalecido y articulado con otras organizaciones populares. Ejemplo de esto es la formación de organizaciones con una activa participación del movimiento estudiantil como el Bloque Popular Revolucionario (BPR), a partir de la toma de Catedral Metropolitana como muestra de repudio a la masacre del 30 de julio, las Ligas Populares 28 de Febrero (LP-28) y el Frente de Acción Popular Unificada (FAPU). Asimismo, los asesinatos del rector Carlos Alfaro Castillo y del decano de la Facultad de Ciencias Económicas, Carlos Alberto Rodríguez, marcan un parteaguas en la radicalización de la lucha estudiantil (Quezada y Martínez, 2008, p. 59).

Durante la década de 1980, el campus central de la UES se convertiría en un espacio neurálgico para la organización del movimiento popular y políticomilitar al punto de ser señalado como un refugio de comunistas y terroristas por la Junta Revolucionaria de Gobierno que se había instalado en el poder en 1979. El 26 de junio de 1980 el campus universitario es nuevamente intervenido 
militarmente, prolongándose su ocupación por tres años, 10 meses y 26 días y dando lugar en 1982 a lo que se conocería como la "Universidad en el exilio", es decir, la reapertura de actividades académicas en espacios alquilados de San Salvador, Santa Ana y San Miguel (Quezada y Martínez, 2008, p. 82).

Durante la primera mitad de la década de 1980, el movimiento estudiantil universitario fue decididamente perseguido por la dictadura militar y varios de sus militantes fueron perseguidos, capturados, asesinados, desaparecidos o exiliados y otros se incorporaron a las filas guerrilleras del FMLN, conformado oficialmente el 10 de octubre de 1980. La beligerancia del movimiento estudiantil durante la segunda mitad de la década se acentúa significativamente y para los años cercanos a la "Ofensiva hasta el tope" de 1989, varios estudiantes ya habían recibido instrucción militar, en coordinación con miembros del FMLN, tanto como recurso defensivo durante las marchas y protestas como en preparación para incorporarse a la ofensiva (Quezada y Martínez, 2008, p. 119).

Con la "Ofensiva hasta el tope y punto" el FMLN demostró, primero, que su fuerza y alcance militar no se limitaba a las zonas ocupadas del nororiente y noroccidente del país, sino que podía organizar un asalto a la capital y llevar la guerra hasta las puertas de la oligarquía y, segundo, la inviabilidad de resolución del conflicto por la vía militar, pues ni la guerrilla logró tomarse la capital, ni el ejército logró neutralizarla por completo. En el operativo participaron muchos estudiantes en tareas logísticas o de combate, cayendo muchos en colonias cercanas al campus universitario.

Otros sucesos de ese mismo año, como la masacre de los seis padres jesuitas de la Universidad Centroamericana "José Simeón Cañas" con una ayudante y su hija, marcaron el inicio del fin del conflicto, a pesar de que se habían sostenido varios diálogos por la paz desde 1984. El camino hacia la firma de los acuerdos de paz de 1992 se hace entonces más claro, caracterizándose esta etapa de negociaciones por una agenda clara con temas y plazos definidos, el establecimiento de mediadores y consultas de los que derivarían eventualmente los acuerdos firmados el 16 de enero de 1992 en el Castillo de Chapultepec, México (López, Quinteros y Ramos, 2015, p. 17).

Este breve esbozo histórico de la larga trayectoria de AGEUS permite valorar su importancia en la historia de los movimientos sociales de El Salvador, que radica tanto en su lucha por la protección del derecho a la educación superior pública como en su articulación con otros movimientos sociales, especialmente el magisterial, en coyunturas de gran trascendencia como la insurrección de 1932, la huelga de brazos caídos de 1944, las olas de protesta de las décadas de 1960 y 1970 y su alineación con las organizaciones político-militares coordinadas con el FMLN durante la guerra civil. La constante presencia de los estudiantes universitarios en todas estas luchas, de acuerdo con Paul Almeida (2011, p. 20), se puede comprender por la movilización 204 impulsada por la intimidación multidimensional del Estado manifiesta en los 
problemas económicos, el progresivo socavamiento de los derechos civiles y la represión estatal a los movimientos sociales.

Se puede sostener, en este sentido, que la AGEUS logró resistir a algunas de las coyunturas de mayor represión y agitación política en las que su militancia puede considerarse de alto riesgo y su actividad se tuvo que mantener en la clandestinidad. Con los reajustes políticos, económicos y sociales augurados por el fin de la guerra, AGEUS inició su último período de actividad en un contexto en el que las nuevas alineaciones y alianzas políticas reordenaron el escenario de operaciones de los movimientos sociales en El Salvador.

\section{El impulso del neoliberalismo en El Salvador de posguerra}

La firma de los Acuerdos de Paz el 16 de enero de 1992 supuso para El Salvador el inicio de un proceso de reordenamiento de fuerzas políticas y sociales y la construcción de un nuevo contrato social en el que se pretendía dejar en el pasado las largas décadas de autoritarismo, represión y agitación política. Doce años de guerra civil y dos décadas de conflicto armado dejaron como saldo decenas de miles de muertos, desaparecidos, desplazados y heridos, así como otras decenas de miles de excombatientes desmovilizados, tanto del FLMN como de la fuerza armada, que se enfrentaban al reto de construir un nuevo proyecto de vida4

Las principales conquistas que se lograron con la salida política de la guerra civil fueron la desmilitarización del Estado, la desaparición de cuerpos de seguridad represivos como la Policía de Hacienda, la Guardia Nacional y los Batallones de Infantería de Reacción Inmediata (BIRI), la transición de una policía militarizada a una civil, la consolidación de un régimen electoral democrático y asegurar la legalización del FMLN como partido político, entre otras. Es, sin embargo, importante señalar que las brechas económicas de desigualdad e injustica social que se habían consolidado desde las primeras décadas del siglo XX, no lograron superarse.

Con la llegada al poder del partido Alianza Republicana Nacionalista (ARENA) en 1989 El Salvador comenzó un acelerado y decidido giro hacia el neoliberalismo. Durante la siguiente década, los gobiernos de Alfredo Cristiani (1989-1994) y Armando Calderón Sol (1994-1999) implementaron reformas económicas orientadas a la reducción del sector público dentro de un planteamiento económico ortodoxo de reducción del déficit público y de provisión de recursos para hacer frente a la abultada deuda externa. Durante estos años se reprivatizó la banca y el comercio exterior del café y el azúcar,

$4 \quad$ Ralph Sprenkels (2014) plantea una periodización del proceso revolucionario salvadoreño que se divide en: conflicto armado, que inicia con la escalada de violencia represiva del Estado, desde 1970 hasta 1992, y guerra civil, que se prolonga desde la "Ofensiva final" en 1981 hasta 1992. 
se produjo la venta de las principales empresas y servicios públicos como la Administración Nacional de Telecomunicaciones (ANTEL), la distribución de energía eléctrica, los ingenios azucareros y del sistema de pensiones (Martín, 2013, p. 66).

Todas estas medidas, sin embargo, no fueron recibidas en silencio por la sociedad civil. Durante la década de 1990, diversos sectores se aglutinaron en coaliciones con fuerte capacidad de movilización, convocando a los ciudadanos directamente afectados por las medidas de reajuste estructural a las calles una vez más. De acuerdo con Martín (2013, p. 66), los actores principales de estas movilizaciones serían trabajadores del sector público, obreros, campesinos, estudiantes, oenegés de desarrollo, organizaciones de mujeres y ambientalistas.

Estas alianzas, a pesar de la importante resistencia que presentaron al viraje neoliberal impulsado por los primeros dos gobiernos de ARENA no lograron, de acuerdo con el autor, articular sus luchas durante esta década y su principal aliado político, el recién fundado partido FMLN, tampoco tenía capacidad en aquel momento para evitar la aprobación de esas medidas en el trámite legislativo (Martín, 2013, p. 66). Es importante destacar que los vínculos entre el FMLN y el movimiento social se habían debilitado significativamente con el fin de la guerra puesto que el proyecto de construcción del partido extrajo de sus filas la mayoría de cuadros de liderazgo, desarticulando importantes esfuerzos organizativos y acoplándose a las reglas del sistema que alguna vez combatió.

El fin de la guerra civil supuso para el FMLN un replanteamiento de su tarea y quehacer político y social. Anteriormente, la agenda de liberación nacional había absorbido a todos los sectores del movimiento social, alineándolos en tareas de movilización de masas y de lucha política y militar, e incorporándolos a la misma línea de mando que los grupos guerrilleros. Con su institucionalización política como partido, el FMLN entraba a una situación en la que, de hecho, renunciaba a la lucha contra la propiedad privada, la economía de mercado y el sistema capitalista y, con esto, renunciaba también al socialismo (Segovia, 2015, p. 64).

Con la firma de los Acuerdos de Paz, las relaciones del FMLN con los movimientos sociales cambiaron dado que la coyuntura sentó como prioridad ya no la lucha social sino la disputa electoral y, para este propósito, hizo mano de la línea de mando construida en el fragor de la guerra civil para reubicar a sus líderes en las estructuras del partido. La salida masiva de cuadros de liderazgo afectó seriamente a los movimientos sociales en los años de posguerra y dio lugar a nuevas dinámicas de organización dentro del mismo (Segovia, 2015, p. 66).

De acuerdo con Martín (2013, p. 61), esta desvinculación con el movimiento social permitió el surgimiento de nuevas identidades políticas, como el feminismo, 
el indigenismo, los movimientos en defensa de la diversidad sexual y el ambientalismo, que habían sido dejadas de lado por la preminencia la agenda de liberación nacional del movimiento revolucionario. Asimismo, surgieron, según señala el autor, como "estructuras de suspensión", las ONG, que dieron continuidad al activismo y la lucha por las necesidades básicas de los sectores más desfavorecidos con una perspectiva comunitaria en un contexto de pluralismo democrático.

El neoliberalismo en la posguerra, y el reordenamiento de fuerzas políticas y sociales que caracterizó al período, dio lugar a lo que Paul Almeida llama los procesos de "movilización por globalización" en el que se produce un contexto híbrido de oportunidad y amenaza económica. Este contexto se caracteriza por la convivencia de un sistema político en el que se estabilizan el acceso institucional y las elecciones competitivas y se legalizan y protegen los partidos de oposición y las organizaciones civiles con problemas económicos atribuibles al Estado por sus políticas económicas neoliberales (Almeida, 2011, p. 31).

Dicho contexto, de acuerdo con Almeida y Walker (2007, p. 66), dio a las manifestaciones de acción colectiva en El Salvador de posguerra un carácter "defensivo", en cuanto su propósito prioritario era evitar medidas que suponían "males colectivos" que empeorarían las condiciones de vida de diversos sectores sociales. A pesar de los amplios esfuerzos organizativos de los nuevos actores del movimiento social, los programas de modernización económica, particularmente acelerados durante la gestión de Armando Calderón Sol, lograron llevar a cabo la privatización de los servicios mencionados anteriormente y la implementación de otras medidas como el incremento del impuesto general de ventas en un 3 \%, la eliminación de los aranceles de importación y el despido de por lo menos de 15000 empleados estatales (Almeida, 2011, p. 367).

Hubo, sin embargo, de acuerdo con los testimonios que se retoman en este artículo, un intento de privatización que no prosperó como las empresas anteriores: el de la Universidad de El Salvador. A diferencia de otros movimientos sociales, como el magisterial y el de trabajadores del sector salud, el estudiantil universitario no ha recibido particular atención en los estudios de historia reciente probablemente porque sus luchas durante la posguerra, a pesar de solidarizarse con otros sectores, se concentraron en la defensa de la universidad misma y su carácter público.

Es pertinente, en este sentido, señalar que hay pocos trabajos en la historiografía que se dediquen particularmente al análisis de la AGEUS como estructura organizativa a pesar de su longevidad e importancia como organización articulada y articuladora de distintos sectores con los que compartieron luchas antes, durante y después de la guerra civil. Sin embargo, 
es frecuente encontrar a la AGEUS como un actor importante en las discusiones sobre movilización social en la historia política del país.

Uno de los propósitos centrales de este artículo es precisamente recuperar información de estas fuentes secundarias, para situar apropiadamente a la Asociación en la posguerra como una estructura que persistió a muchos de los escenarios más difíciles de la historia del país, e intentar dar algunas luces sobre el período más borroso, por menos estudiado, de su trayectoria, que fue el de la posguerra. Durante los años posteriores a los Acuerdos de Paz, la AGEUS se reestructuró en función de nuevas amenazas y resistencias; proceso que en los escasos trabajos dedicados exclusivamente a la Asociación, como el de Quezada y Martínez (2008), está poco o nada documentado, por lo que se optó por otro tipo de fuentes que dieran cuenta de los acontecimientos que condujeron a su eventual disolución.

Por este motivo, se recurrió a fuentes orales que dieran cuenta de los procesos de reorganización, lucha y negociación por los que pasó la AGEUS en la etapa previa a su disolución. Estas entrevistas fueron realizadas en el año 2013 por los autores Ricardo Alejandro Durán Rodríguez y Ricardo Ernesto Rivera Chinchilla, en el marco de un estudio de finalización de pregrado en el que se analizaba el funcionamiento de la Asociación durante los períodos de la guerra civil y la posguerra con el objetivo de comprender la relación entre las condiciones históricas desde las cuales varios estudiantes ejercieron su militancia y sus formas de crear identidad, organizar su actividad a nivel interno y externo (con otros grupos) y administrar el poder (Durán, Henríquez y Rivera, 2014).

El instrumento, una entrevista semiestructurada, fue adaptado a los contextos correspondientes de cada participante y se lograron concertar a través de cadenas de referencias de los mismos militantes que sostenían contacto con algunos de sus excompañeros. A pesar de que el cuerpo de entrevistas es más amplio, para usos de este artículo se retoman dos de las más representativas en lo que respecta a contenidos y posturas explicativas sobre el proceso de desarticulación de la Asociación, esperando que sus memorias representen un aporte al poco material acerca de esta etapa que se puede encontrar en la historiografía sobre la materia.

Aún silainformación obtenida de los participantes no puede serconsiderada concluyente sin un análisis más profundo, sí es importante reconocer en ella varios elementos que embonan muy bien con las características del contexto al que se refieren y abren posibilidades para orientar futuras discusiones sobre el tema. La desarticulación del movimiento estudiantil universitario fue producto, según sus testimonios, de pugnas, contradicciones y desacuerdos dentro del mismo movimiento, pero también puede considerarse un caso sintomático del desmantelamiento del movimiento social producido por la 
extracción de cuadros de liderazgo que llevó a cabo el FMLN en su afán de consolidación como partido político.

Fenómenos como el vacío generacional de líderes dentro del movimiento estudiantil, los desencuentros de este con las autoridades universitarias, alineadas en su mayoría con el FMLN, y con el partido que surgió de este posterior a su desarme, así como la proliferación de organizaciones cada vez más radicales dentro de la universidad, marcaron decididamente a la AGEUS durante el período de su última lucha por el derecho a la educación superior. Las memorias retomadas a continuación dan cuenta de estos procesos y del logro más importante de este período, que fue la participación de los estudiantes en la formulación de la Ley Orgánica de la UES, aprobada el 25 de mayo de 1999.

\section{El resurgimiento de la AGEUS en la posguerra desde la memoria de dos exmilitantes}

Los testimonios presentados a continuación son retomados de entrevistas a exmilitantes de la AGEUS en el período comprendido entre los años 1992 y 2000, quienes fueron tanto miembros como dirigentes del movimiento universitario. Es necesario insistir en que la información presentada no pretende ser una historia oficial de los procesos que llevaron a la disolución de la asociación, sino elementos de la versión presentada por dos de sus militantes que dan cuenta de los procesos referidos en el apartado anterior sobre la influencia del contexto de neoliberalismo en la posguerra en la actividad del movimiento estudiantil universitario.

El primer fenómeno señalado por los participantes con respecto al papel de la AGEUS durante el período de posguerra es el vacío generacional producido por la extracción de cuadros de liderazgo de la Universidad Nacional que realizó el FMLN para su consolidación como partido político. Dicha extracción es posible debido a la línea de mando, consolidada durante la guerra civil, que atravesaba tanto a las organizaciones político-militares como al movimiento social:

cuando llegan los Acuerdos de Paz ... hay en el FMLN la necesidad de construirse como Partido ... Prácticamente un poquito antes de los Acuerdos de Paz el FMLN comienza a extraer cuadros de la Universidad, a sacar una gran cantidad de jóvenes que venían de una gran tradición de lucha y los empieza a colocar en estos lugares. Entonces la Universidad queda como en un vacío generacional ... [durante la guerra] se perdió la independencia entre lo que era el movimiento social como tal, es decir, sindicatos, organizaciones de masas y las estructuras político-militares ... este desarrollo paralelo que debían llevar los movimientos sociales y las organizaciones armadas se fusiona y se vuelve vertical. Es decir, todas las organizaciones sociales, aunque no estuvieran armadas, respondían a una línea de carácter militar. Entonces esa jerarquía militar es una de las razones por las que el Movimiento Estudiantil es mucho más beligerante, mucho más ... 
virulento en ciertas etapas, específicamente entre el 85 y el 88 (M. V., militante de AGEUS periodo 1992-2000) ${ }^{5}$.

El resultado de este proceso de concentración de liderazgos fue, desde esta perspectiva, la consolidación del FMLN como partido político, pero también el descuido del movimiento social. Durante los años 1992 y 1993, esta ausencia de dirección comenzaría a cobrar relevancia por lo que los entrevistados evalúan como un periodo de intenciones privatizadoras de la universidad:

En el caso de la Universidad digamos que es a lo que nos enfrentamos a nivel de ahí por el 92-93 ... la Universidad comienza un proceso de, lo que nosotros llamábamos en aquel momento, y que fue tachado como radicalismo, de privatización ... es decir, comenzar a ceder muchas de las conquistas que tenía la Universidad en términos de gratuidad de la educación, paridad estudiantil, esos acuerdos para nosotros todavía estaban vigentes, pero ellos comienzan como a querer comercializar, mediatizar, y eso es lo que le da impulso al movimiento en el que nosotros entramos. Nosotros somos hijos, primero de la posguerra y segundo de la implementación del Neoliberalismo en toda la década de los 90's y sus efectos en la Universidad (M. V., militante de AGEUS periodo 1992-2000).

Es importante, sin embargo, señalar que durante estos años se reincorporaron a la comunidad estudiantil de la UES excombatientes con la intención de finalizar sus carreras y, a pesar de que se negaron a tomar el liderazgo del movimiento universitario, ofrecieron alguna orientación a la nueva generación que eventualmente refundaría la AGEUS:

En el '93 regresan a las facultades un montón de estudiantes que fueron estudiantes en el período de los 80's - 70's que se fueron a la guerra ... que sobrevivió a la guerra obviamente y querían terminar sus carreras ... como el FMLN te deja un vacío generacional al quitarte todos los cuadros que tenían el mapa de la cuestión estudiantil, pero regresan no con la intención de reorganizar el movimiento estudiantil sino con intenciones personales de terminar una carrera que la dejaron abandonada ... muchos compañeros que conocieron la tradición del movimiento estudiantil, de la AGEUS, de toda esa lucha con otros métodos en años anteriores, empiezan y son los que de alguna manera te empiezan a decir [orientar en la organización] (M. V. militante de AGEUS periodo 1992-2000).

El año que marcó la reorganización de la AGEUS fue 1997. El nuevo ingreso de ese año dejó fuera a muchos aplicantes que habían pagado por su proceso de admisión, creando un fuerte descontento. Al comparar las cifras de ventas de aplicaciones con las de proyecciones de aceptación, las pocas organizaciones activas dentro de la universidad comenzaron a sospechar de una intención de privatización:

se da un fenómeno en el nuevo ingreso del 97, que la gente comienza a hacer sus trámites en el 96. Empezamos a ver que habían alrededor de ... cerca de

$5 \quad$ En este apartado se utilizarán solamente las iniciales de los participantes, con el fin de diferenciarlos, y no sus nombres completos puesto que el consentimiento informado firmado por los participantes para su participación en el estudio mencionado al inicio de este artículo contempla explícitamente el uso de sus nombres solamente para fines de esa investigación. 
1500 o 1800 estudiantes o más que trataron de ingresar a la Universidad y ellos habían vendido, bueno, reportaban haber vendido 1800 solicitudes a un precio que no recuerdo ahorita ... Entonces sacamos cuentas, cuánto vendieron, y sabemos por producción que habían vendido cerca de 2,200 solicitudes para que ingresaran estudiantes y ellos tenían pensado agarrar sólo 900 personas ... Entonces había un descontento ... esas fueron como las primeras medidas en el tema de privatización de la universidad que a todos nos hizo parar las orejas ( $M$. V., militante de AGEUS periodo 1992-2000).

La segunda razón por la que se comenzó a sospechar de una intención privatizadora dentro de la Universidad fue el perfil económico de los estudiantes que sí fueron aceptados. De acuerdo con los entrevistados, se priorizó el ingreso de personas con capacidad de pago, tanto por intereses económicos como para impulsar un proceso de despolitización de la universidad:

la línea era la privatización de la $U$, pero ellos no lo iban a hacer al estilo como privatizaron los bancos ... no lo iban a hacer de esa manera, era una manera mucho más sutil ... empezaron a privilegiar el ingreso de estudiantes que venían de colegios, o sea, empezaron a clasificar a los estudiantes ... el plan era empezar a sacar de la Universidad a estudiantes que vinieran de estratos pobres porque generalmente la gente que se organizaba y que defendía conquistas de la Universidad, el estudiante que se politizaba más es el estudiante que viene de los sectores más pobres (M. V., militante de AGEUS periodo 1992-2000).

Cuando se presentó la coyuntura del nuevo ingreso de 1997 dentro de la UES funcionaban más los gremios, grupos articulados alrededor de intereses culturales o de activismo social, que las asociaciones estudiantiles. Sin embargo, en facultades como Derecho y Agronomía los estudiantes rechazados encontraron alguien con quien compartir su descontento y esto movilizó el acercamiento entre los gremios y asociaciones que persistían dentro de la universidad:

los estudiantes de nuevo ingreso como que andaban buscando a qué santo arrimarse ... el estudiante como no había quien respondiera a sus demandas en las otras facultades andaban de facultad en facultad preguntando "miren ¿hay organización estudiantil acá? ... Váyase a Agronomía, a los de Agronomía, a esos locos ya tienen una organización ahí” ... Entonces ahí comenzó el tema de la AGEUS ... empezamos a hablar con los pequeños grupos, algunos ya eran asociaciones estudiantiles, otros eran gremios ... nosotros teníamos el MECA, que era el movimiento ecológico ... Tuvimos que empezar a inventar cómo hacía la gente antes para organizar a los estudiantes y que se volviera a interesar en el tema de la Universidad (M. V. militante de AGEUS periodo 1992-2000).

En el 97, cuando nosotros en la facultad de derecho ganamos las elecciones empezamos a vincularnos con otras asociaciones estudiantiles, entre ellas estaba la FECAS, la CYA de ingeniería, la CEMEA de medicina y empezamos a llegar a la AGEUS junto con estos compañeros que se mantenían ese cascarón (A. A. militante de AGEUS periodo 1992-2000). 
La coyuntura de 1997 llevó a la organización de una asamblea estudiantil, con una importante convocatoria, de la que surgiría un nuevo comité ejecutivo provisional de la AGEUS. Las voces sobre este esfuerzo de revitalización del movimiento estudiantil universitario llegaron hasta los campus de oriente y occidente y, con esto, inicia la articulación del campus central con las paracentrales de la UES y acciones de protesta, en solidaridad con otros sectores que también estaban siendo objeto de privatización, que toman como consigna un contundente "privaticen a su madre":

con un esfuercito así empezaron a nacer las demás asociaciones. En ese entonces de las 12 que había a nivel nacional, 12 facultades, en la central hay nueve, de esas prácticamente sólo cinco estábamos organizadas ... en el 97 convocamos una asamblea, nos llegaron cerca de 700 personas ... lo que surgió de ese fenómeno fue la reconstrucción, con estas cinco organizaciones, del comité ejecutivo provisional de AGEUS (M. V. militante de AGEUS periodo 1992-2000).

[Cuando se solicitaba el apoyo de la AGEUS para marchas] miren compañeros, tenemos una marcha para tal día contra la privatización de ANTEL, de las pensiones, nosotros íbamos, de hecho, en ese entonces yo recuerdo que alguien, un estudiante con mala ortografía, no recuerdo quién, empezó a pintar en las calles y se hizo bastante popular esa consigna, bastante malcriada pero bastante eficaz: "privatizen a su madre" y con z [ríe]. Pero empezó a pegar, "privaticen a su madre" (A. A. militante de AGEUS periodo 1992-2000).

De repente [se establece contacto con] facultades con las que no teníamos ninguna relación, como el caso de la facultad en oriente, San Miguel, San Vicente y Santa Ana ... Entonces logramos prácticamente tener 8 facultades de las 12 a nivel de la Universidad alineadas ... y la consigna fue esa la no privatización de la U. Salía una consigna malcriada: "privaticen a su madre". Se ponían en los carteles: "privaticen a su madre, no a la UES" (M.V. militante de AGEUS periodo 1992-2000).

La reorganización de los estudiantes y las crecientes protestas, por medidas como la clasificación de los aplicantes en función de su poder adquisitivo, generaron respuestas tanto dentro de la universidad como del FMLN, puesto que la mayoría de las autoridades que administraban la universidad en ese momento eran cuadros del frente.

Ya habíamos tenido reacciones de las autoridades. Nosotros creemos que incluso del FMLN. Porque la mayoría de las autoridades que en ese momento manejaban las riendas de la Universidad, tanto en Rectoría, en el Consejo Superior Universitario, que es el conjunto de todas las facultades, la mayoría eran cuadros del FMLN ... Entonces empezó como una persecución (M.V militante de AGEUS periodo 1992-2000).

Lo escasos recursos con los que contaba el resto de las organizaciones se conseguían a partir de alianzas estratégicas con comerciantes y trabajadores dentro y fuera de la universidad que, si bien, no podían aportar con dinero sí les apoyaron con materiales. Esto marca un importante restablecimiento 212 de alianzas entre sectores que también se había perdido con la decadencia 
de la actividad estudiantil universitaria producto de la cooptación de líderes ejecutada por el FMLN-partido:

Los recursos que nosotros teníamos eran arrancados, por decirte algo, si necesitábamos reunirnos una noche para conspirar toda la noche nos quedábamos 10-15 de varias facultades, había una campañita en la tarde de ir a todos los cafetines "mire, nos vamos a quedar, ¿nos regala comida?" ... Los trabajadores entendían muy bien, ellos también estaban siendo víctimas de todo este paquetazo. Ellos nos apoyaron mucho, no sólo trabajadores de la U sino que trabajadores de fuera, de los empleados públicos. Nunca nos dieron dinero, sino que nos dieron materiales, fue muy interesante esa relación con el sector trabajador (M. V. militante de AGEUS periodo 1992-2000).

Al consolidarse la reactivación de la AGEUS con la asamblea de 1997, el movimiento estudiantil universitario se enfrentó a la coyuntura que marcaría su actividad durante esta década y su mayor logro: las negociaciones alrededor de la ley orgánica de la UES:

el fenómeno de la Ley Orgánica en la Universidad que fue un, casi saliendo del congreso ya teníamos a las puertas esa coyuntura. La Ley Orgánica de la Universidad la estaban transformando ... si vos transformás las leyes de la Universidad vos podés darle ... ahí está el andamiaje jurídico para vos poder convertir una universidad, sin llamarle privada ... nosotros nos metemos de lleno a la Ley Orgánica de la U ... eran dos banderas de lucha, una la paridad estudiantil, le decíamos nosotros, y la otra la gratuidad de la educación. Fueron como las dos banderas con las que nosotros entramos al debate en la Ley Orgánica de la U (M.V. militante de AGEUS periodo 1992-2000).

Las autoridades universitarias, sin embargo, trataron de mantener a la AGEUS fuera de las negociaciones, con el argumento de su ilegalidad o falta de reconocimiento institucional, e incorporar a otros representantes de los intereses estudiantiles más "despolitizados":

como tenían problemas con nosotros ... decidieron "no, no vamos a llamar a estos que se llaman AGEUS porque son ilegales, vamos a ir a traer a los estudiantes con el mejor [promedio] de la Universidad, a esos estudiantes los vamos a llamar y estos van a ser la comisión que va ir a hablar con los diputados". (M. V. militante de AGEUS periodo 1992-2000).

Esta estrategia no logró la aceptación de la comisión negociadora de la Asamblea Legislativa y se procedió a convocar a representantes de la AGEUS que presentaron las dos banderas de lucha como peticiones oficiales del sector estudiantil:

Entonces vino la gente de la comisión y dijo "No, nosotros queremos hablar con los estudiantes, no con los alumnos, una cosa es ser alumno y otra cosa ser estudiante. Ustedes nos han traído aquí alumnos, aplicados, pero normalmente al alumno aplicado no le interesan los problemas de la Universidad. Entonces queremos a los estudiantes, ¿dónde están?” ... Fue así como llegó una delegación de nosotros a regañadientes de las autoridades. Y nos plantearon "¿bueno cuáles son sus expectativas con la Ley Orgánica?”. Dos cosas: una, la paridad estudiantil. 
-Ajá cuando se refieren a paridad estudiantil ¿qué quieren?, ¿cuánto poder quieren?, ¿cuántos estudiantes? -No, nosotros no queremos poder, queremos equilibrio de fuerzas en la $U$... Con el tema de la gratuidad no [se tuvo la misma aceptación] (M. V. militante de AGEUS periodo 1992-2000).

El argumento de la comisión de la Asamblea Legislativa para rechazar la propuesta de gratuidad de la educación era que no todos los estudiantes en la UES eran de escasos recursos y que, por lo tanto, sería injusto que fuera gratuita para todos. Esto llevó la discusión a un tema más engorroso, la reforma fiscal, que fue también rechazado por la comisión:

[planteamos que] si aquí hubiera un justo pago de impuestos que, el estribillo ese que pusieron de moda ahora, "el que tiene más que pague más, el que tiene menos que pague menos" ... Que el que tiene recursos pague de acuerdo a lo que gana y el que no, tampoco. Entonces cuando los que paguen más, paguen lo justo, pueden mandar a sus hijos a estudiar de manera gratuita a la Universidad porque ya pagaron. Ahí ya no les gustó. Ahí ya no les gustó porque entonces nos metíamos al tema de reforma fiscal (M. V. militante de AGEUS periodo 1992-2000).

Así, como resultado de las negociaciones, se contempló en la Ley Orgánica de la UES la paridad estudiantil que garantizaba representación con voz y voto del sector estudiantil en la Asamblea General Universitaria (AGU). La gratuidad de la educación, sin embargo, no fue aceptada y se optó por un sistema de cuotas diferenciadas. Esto marcaría tanto el mayor logro, como el mayor fracaso del movimiento estudiantil durante esta década:

por el lado de la gratuidad fue un fracaso político nuestro, no tuvimos la correlación con la sociedad de que la sociedad entendiera que el tema de justicia en la Universidad estaba más allá de las puertas de la Universidad ... Con el tema de la paridad pues al menos, si en la Ley Orgánica revisan, por lo menos está ese nivel de paridad y en términos de lo que era la AGEUS yo ahí sí considero que fue un error no darle seguimiento a las estructuras de hecho que ya existían (M. V. militante de AGEUS periodo 1992-2000).

De acuerdo con ambos participantes es, irónicamente, después de este período de reorganización cuando su legalización como organización estudiantil y el logro de la paridad estudiantil que la AGEUS comienza a debilitarse. Los dos factores más influyentes en este proceso que terminaría con la disolución de la asociación fueron el sometimiento a las normas y reglamentos de la universidad, que incluyeron en la AGU solamente a estudiantes que cumplían un perfil académico sobresaliente, y, segundo, el surgimiento de organizaciones dentro del movimiento universitario que no reconocían la legitimidad de la AGEUS como representantes del sector estudiantil y promovían un comportamiento más cercano a los grupos de choque:

Los dirigentes de la AGEUS que quedaron creo que le pusieron demasiada fe, siento yo, a que los estudiantes que iban a estar en los órganos de dirección eran los que iban a lograr que la Universidad para el tema de la privatización ... los criterios [para ser elegible] ique tenías que tener un CUM de no sé cuánto! Entonces de ese grupito de nerds tenías que elegir a tu representante estudiantil 
en el Concejo y en la junta de directores por facultad, sabías que ese tipo lo que menos le importaba quizás era la $U$... la paridad estudiantil quedó ahí en la Ley Orgánica, pero tenían que ser estudiantes que demostraran capacidades académicas, desde ese momento ahí estaba la trampa, ahí era la trampa (M. V. militante de AGEUS periodo 1992-2000).

ellos no se sentían parte y además tenían mayor correlación porque ya habían crecido, ya tenían muchas personas, muchos estudiantes organizados y también tenían presencia en las calles. Ellos reformularon lo que AGEUS dejó. Se vincularon con los sindicatos en las calles; UERS-30, BRES. La BRES para ese tiempo estaba pequeñita pero el UERS-30 era más grande (A. A. militante de AGEUS periodo 1992-2000) ${ }^{6}$.

Las contradicciones y disputas dentro del movimiento universitario escalarían hasta un desenlace dramático en la asamblea general de 1998 en la que se pretendía elegir el nuevo comité ejecutivo de la AGEUS. Los grupos antes mencionados habían crecido significativamente en militancia y la legitimidad de la AGEUS se había desgastado debido al fracaso parcial del esfuerzo por la paridad estudiantil y otros fenómenos que provocaron descontento entre la comunidad estudiantil, como los repetidos viajes de comitivas de AGEUS a conferencias y cumbres estudiantiles en el extranjero:

la UERS-30 que había crecido bastante, y la BRES. Se van a meter al auditorio ... Llegaron con las varillas, llegaron amenazantes, empañoletados como si iban a golpear a la gente que estaba en el congreso. El objetivo era desarmar. ¿Por qué? Porque ellos no se sentían representados (A. A. militante de AGEUS periodo 1992-2000).

En el camino creo que aparecieron estas otras organizaciones que al final le dieron al traste a la AGEUS. Entiendo que la UERS, yo ya no estaba en ese tiempo, pero entiendo que se tomaron el Congreso ... pensaron que con el triunfo que se tuvo con lo de la paridad estudiantil en la Ley Orgánica ya se había resuelto todo y era cuando había que fortalecer más la organización, no lo hicieron, al contrario, empezaron a separarse de muchas organizaciones con las que habíamos construido alianzas a fuerza de lo que yo te explicaba... ellos lo fueron abandonado y se crearon esas divisiones. Estas organizaciones movidas por no sé qué intereses, nunca pude determinar qué intereses habían detrás de estas organizaciones (M. V. militante de AGEUS periodo 1992-2000).

Esta es la última asamblea que, según los participantes, convocó la AGEUS, marcando la disolución de la asociación. En la década siguiente las organizaciones mencionadas, UERS-30 y las BRES tomarían un papel cada vez más protagónico en las luchas universitarias, especialmente aquellas orientadas al ingreso de estudiantes rechazados en los procesos de admisión.

$6 \quad$ UERS-30: Unión de Estudiantes Revolucionarios Salvadoreños "30 de julio”; BRES: Brigadas Revolucionarias de Estudiantes Salvadoreños. 


\section{Conclusiones}

La desarticulación de la Asociación General de Estudiantes Universitarios Salvadoreños (AGEUS) es un caso sintomático de los efectos del contexto neoliberal de El Salvador de posguerra en los movimientos sociales, y es particularmente interesante por la larga tradición de lucha de la organización y su vinculación tanto con personajes como con coyunturas icónicas de la lucha revolucionaria en el país. Después de persistir más de medio siglo de dictaduras militares y una guerra civil, la AGEUS desaparece en un contexto en el que las nuevas garantías sociales deberían haberla hecho crecer.

Es también un caso representativo de cómo la cooptación de cuadros de liderazgo en el proyecto político electoral del FMLN afectó enormemente a los movimientos sociales dejándolos, primero, sin líderes experimentados y, segundo, sin una dirección política definida que asegurara su continuidad. Irónicamente, es después de su legalización que la asociación pierde convocatoria y legitimidad, dando fin a una larga tradición de lucha estudiantil y articulación con otros sectores y causas sociales.

El momento de transición por el que pasó el país a principios de la década de 1990 fue decisivo para definir el carácter de las problemáticas sociales que darían lugar al nuevo conflicto social a partir del año 2000. Con la izquierda ocupada en su consolidación como partido, la derecha en el poder y el movimiento social acéfalo y sin dirección, el proyecto neoliberal logró importantes conquistas que no podían ser respondidas desde los nuevos márgenes de legalidad que se construyeron a partir de los Acuerdos de Paz.

Aun con estas condiciones, las luchas sostenidas por las nuevas generaciones de estudiantes universitarios para frenar las intenciones de privatización de la única universidad pública del país, articuladas con las de otros sectores que resistieron hasta entrada la década del 2000 para frenar, por ejemplo, el proyecto de privatización de la salud, demostraron que la sociedad salvadoreña de posguerra no estaba dispuesta a aceptar estas reformas en silencio. A pesar de que actualmente no pueda hablarse de un movimiento estudiantil articulado y activo en la vida política del país, las conquistas de las luchas de esta década siguen vigentes hasta el día de hoy.

En este artículo se han retomado como fuentes orales las versiones de dos personas, entonces militantes, que dan cuenta de estos procesos desde su posición como relevo generacional y como parte de un esfuerzo de rearticulación de una organización con la talla histórica de la AGEUS. Quedan pendientes, sin embargo, las versiones que puedan aportar, por ejemplo, las autoridades universitarias del momento, estudiantes organizados en otras asociaciones y gremios y las fuentes documentales que puedan existir de las negociaciones de la ley orgánica. 
La conservación de la memoria sobre este período, generalmente opaco y difuso por su misma naturaleza transicional, podría dar importantes aportes a la comprensión de muchos de los problemas actuales del deprimido movimiento social salvadoreño y de la influencia del contexto "híbrido" de posguerra, en términos de Almeida, en la movilización social frente al neoliberalismo. Asimismo, permitiría ampliar la comprensión del proceso de transformación política del mismo FMLN que, con el fin de la guerra, se desvincula, primero, del proyecto de liberación nacional y las causas populares, y después del movimiento social, conservando solamente un revestimiento histórico de su pasado revolucionario muy distante de su actual comportamiento político que, al día de hoy, hace cada vez menos creíble su discurso como partido de izquierda.

\section{Referencias}

Almeida, Paul y Walker, Erica. (2007). El avance de la globalización neoliberal: una comparación de tres campañas de movimientos populares en Centroamérica. Revista Centroamericana de Ciencias Sociales, 4(1), 51-76.

Almeida, Paul. (2011). Olas de movilización popular: movimientos sociales en El Salvador 1925-2010. San Salvador, El Salvador: UCA Editores.

Anderson, Thomas. (1971). El Salvador, 1932. Los sucesos políticos. San Salvador, El Salvador: Dirección de Publicaciones e Impresos.

Cabarrús, Carlos. (1983). Génesis de una Revolución: análisis del surgimiento y desarrollo de la organización campesina en El Salvador. México D. F.: Ediciones de la Casa Chata.

Ching, Erik; Tilley, Virginia y López, Carlos Gregorio. (2007). Las masas, la matanza y el martinato en El Salvador. Ensayos sobre 1932. San Salvador, El Salvador: UCA Editores.

Dalton, Roque. (1997). Miguel Mármol. Los sucesos de 1932 en El Salvador. San Salvador: UCA Editores.

Durán Rodríguez, Alejandro; Henríquez Chávez, Alan y Rivera Chinchilla, Ricardo. (2014). La Asociación General de Estudiantes Universitarios Salvadoreños (AGEUS) como grupo en los contextos socio-históricos de 1984 a 1991 y de 1992 a 200: abordaje desde un modelo psicosocial. (Tesis de licenciatura en Psicología). Universidad Centroamericana José Simeón Cañas, Antiguo Cuscatlán, El Salvador.

López, Oswaldo; Quinteros, Carolina y Ramos, Carlos. (2015). Reforma del Estado después de los Acuerdos de Paz: Negociando e implementando un acuerdo político inclusivo en El Salvador. Inclusive Political Sttlements, (14), 1-24. 
Martín Álvarez, Alberto. (2013). Sociedad civil y movimientos sociales en El Salvador de postguerra. Historia Actual Online, (32), 59-71.

Quezada, Rufino y Martínez, Hugo. (2008). 25 años de estudio y lucha (Una cronología del movimiento estudiantil). San Salvador, El Salvador: Editorial Universitaria.

Segovia, Alexander (Coord.). (2015). Los movimientos sociales en sociedades posbélicas: la experiencia de El Salvador. San Salvador, El Salvador: FLACSO El Salvador.

Sprenkels, Ralph. (2014). Las relaciones urbano-rurales en la insurgencia salvadoreña. En Jorge Juárez (Ed.), Historia y debates sobre el conflicto armado salvadoreño y sus secuelas (pp. 25-44). San Salvador, El Salvador: Instituto de Estudios Históricos, Antropológicos y Arqueológicos.

Turcios, Roberto. (2015). La vida política. En Carlos López Bernal (Ed.), El Salvador: Historia contemporánea (pp. 53-127). San Salvador, El Salvador: Fundación MAPFRE.

Walter, Knut. (2015). Población y sociedad. En Carlos López Bernal (Ed.), El Salvador: Historia contemporánea (pp. 267-334). San Salvador, El Salvador: Fundación MAPFRE. 